\title{
Vascular Ultrasound in Gynecology
}

\author{
${ }^{1}$ Atsushi Yoshida, ${ }^{2}$ Tsutomu Tabata, ${ }^{2}$ Toshiharu Okugawa, ${ }^{2}$ Takashi Sugiyama, ${ }^{2}$ Norimasa Sagawa \\ ${ }^{1}$ Department of Obstetrics and Gynecology, Nishisaitama-Chuo National Hospital, Saitama, Japan \\ ${ }^{2}$ Department of Obstetrics and Gynecology, Mie University School of Medicine, Mie, Japan
}

Correspondence: Atsushi Yoshida, 2-1671 Wakasa, Tokorozawa, Saitama 359-1151, Japan

Phone:+81-4-2948-1111, Fax: +81-4-2948-1121, e-mail: yoshida.atsushi@nifty.ne.jp

\begin{abstract}
The usefulness of the vascular ultrasound in the filed of gynecology is now well recognized. The intima-media thickness (IMT) and the elastic property of the common carotid artery are reported to be associated with the risk of cardiovascular diseases and are thought to be influenced by menopause. The assessment of the flow-mediated vasodilation (FMD) of the brachial artery is a noninvasive method for the evaluation of vascular endothelial function and is reported to be associated with menopause or hormone replacement therapy. Certain gynecological situations such as contraceptive use or hormone replacement therapy are reported to increase the risk of thrombosis. For the screening of deep vein thrombosis of the lower extremities in the gynecological diseases, compression ultrasonography (CUS) is useful.
\end{abstract}

Key words: Vascular ultrasound, carotid artery, radial artery, flowmediated vasodilation, deep vein thrombosis.

\section{INTRODUCTION}

A great progress has been made in the noninvasive assessment of the blood vessels using ultrasound analysis in the clinical medicine, and the deaths due to cardiovascular diseases were reduced with the progress in diagnostic methods and management of atherosclerotic diseases. Since the risk of cardiovascular disease is high in perimenopausal and postmenopausal women, gynecologists may have to play important roles in the diagnosis and management of the disorders. Since the risks are high for venous thrombosis and pulmonary embolism in some gynecological diseases and situations, the screening of deep vein thrombosis is requested in such gynecological situations as postoperative conditions. We reviewed two topics of vascular ultrasound in gynecology in this article: (i) vascular ultrasound of atherosclerotic diseases in perimenopausal and postmenopausal women, and (ii) screening of deep vein thrombosis in gynecological diseases and surgeries. The results obtained by our own studies in these topics are also discussed in this report.

\section{METHODS}

Ultrasound techniques used in this study were realtime B-mode, color Doppler flow mapping and M-mode ultrasound. The devices of SONOLINE Antares with a 4 to $9 \mathrm{MHz}$ electronic linear and a 2 to $5 \mathrm{MHz}$ electronic compound scan transducer (Mochida Siemens Medical System, Tokyo), LOGIQ 500 MD with a $3.5 \mathrm{MHz}$ electronic compound scan transducer (GE Yokogawa Medical System, Tokyo) and SSD-550 with a $30 \mathrm{MHz}$ mechanical linear scan transducer (Aloka, Tokyo) were used in this study.

We assessed the intima-media thickness of the radial artery by realtime B-mode in 485 normotensive subjects ( 336 men and 27 women), and in 164 patients with hypertensive disorders (137 male and 27 female patients). The elastic property of the common carotid artery was assessed by M-mode ultrasound in 12 normotensive and 20 hypertensive women. The femoral and popliteal veins were studied by conventional B-mode and color flow duplex sonography in the supine position. Deep vein thrombosis was assessed by the technique of compression ultrasonography. We assessed 317 postoperative women consisting of 180 benign abdominal, 115 malignant abdominal and 22 benign vaginal surgeries.

\section{RESULTS}

\section{Vascular Ultrasound of the Atherosclerotic Diseases in Perimenopausal and Postmenopausal Women}

It is well known that the incidence of atherosclerotic disease is high in postmenopausal women. Although the mechanism of its increase has not been completely explained, the elevation of lipids, especially that of LDL cholesterol, is thought to be one of main factors for the developing mechanism. Although the diagnostic accuracy of atherosclerotic vascular disease was improved by the ultrasonography which has been playing an important role in the diagnosis by the combination of B-mode and Doppler ultrasound, we will review mainly the results obtained by B-mode ultrasonography in this report.

\section{Menopause and the Arterial Wall Structure}

The longitudinal image of the arterial wall represents three layers in the high-resolution ultrasound images (a) the innermost first 
echogenic line adjacent to the vascular cavity, (b) the outer hypoechoic line and (c) the second echogenic line. The thickness of the innermost echogenic line does not represent any histological structure but mainly depends on the property of the ultrasound signal. In contrast to the histologic structure, ultrasound overestimates the thickness of the intima and adventitia, and underestimates the thickness of the media. ${ }^{1}$ In 1986, Pignoli and colleagues reported that the distance from the leading edge of the first echogenic line to the leading edge of the hypoechoic line in the arterial wall showed a significant correlation with values of the combined thickness of the intimal and medial layers obtained by histological tissue examination. ${ }^{2}$ This distance is called the intima-media thickness (IMT). Since then, many reports have been published about the arterial wall thickness assessment by high-resolution ultrasound. Most of the reports were made on the common carotid artery. It was reported that the increase of the IMT of the common carotid artery was related to the increased incidence of acute myocardial infarction (AMI) and other coronary artery diseases (CAD). ${ }^{3,4}$ The IMT values of femoral artery ${ }^{5}$ and radial artery ${ }^{6}$ have been published.

It had been known that menopause was related to the increased risk of AMI or CAD and postmenopausal changes of the IMT were reported. ${ }^{7}$ It was also reported that hormone replacement therapy (HRT) for postmenopausal women reduced the IMT, ${ }^{8}$ but HRT did not affect IMT in later studies based on a large number of patients. ${ }^{9,10}$ Elapsed years since bilateral oophorectomy was associated with increased IMT. ${ }^{11}$

We have reported the relationship between the IMT of the radial artery and aging. ${ }^{12} \mathrm{We}$ measured the IMT of radial artery in 649 patients using a $30 \mathrm{MHz}$ mechanical linear transducer (Fig. 1). In the results obtained, the IMT of radial artery was significantly larger in postmenopausal cases than in premenopausal women (Figs 2 to 4 ). The association of increased IMT of radial artery and atherosclerotic diseases was suggested, because the IMT increase was related to the elapsed time after the menopause. It was suggested in our experience that the measurement of IMT in radial artery was useful in the management of postmenopausal women.

The attempt was reported to evaluate the arterial wall stiffness measuring the arterial diameter with high-resolution ultrasonography and the pulse pressure. Westendorp and colleagues ${ }^{13}$ reported that the distensibility of the common carotid artery was negatively affected by menopause. However, HRT did not restore the distensibility of the common carotid artery. ${ }^{14,15}$ Using high-resolution ultrasound, we also measured the elastic property of common carotid artery in normotensive and hypertensive women (Fig. 5). In our results obtained (Table 1), the elastic property in hypertensive women was larger than that in normotensive women. Further study, however, would be extended, because of small number of subjects who were not age-matched in the report.

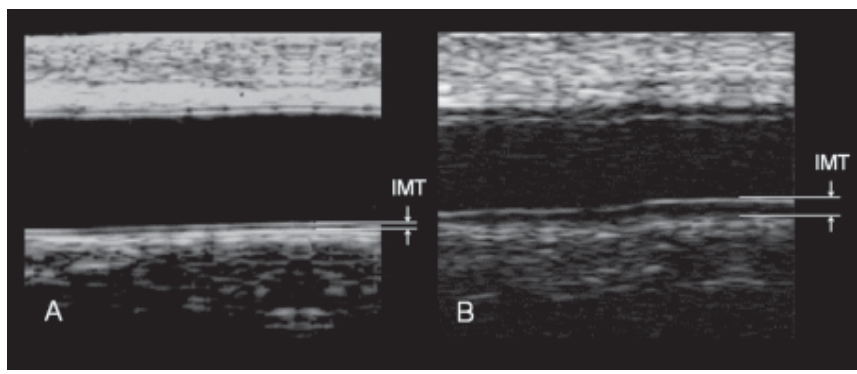

Fig. 1: Two cases of the IMT measurements in the radial artery: $(A)$ 23 years old normotensive woman. IMT $=0.10 \mathrm{~mm}$, (B) 46 years old hypertensive man. IMT $=0.30 \mathrm{~mm}$

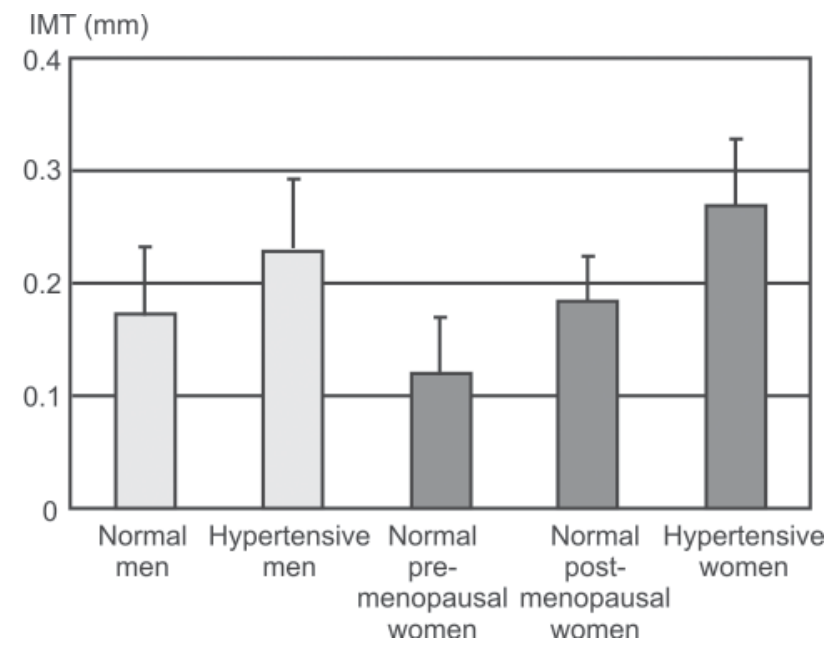

Fig. 2: The IMT of radial artery in the five groups. Vertical bars show the range of +1 SD in each group

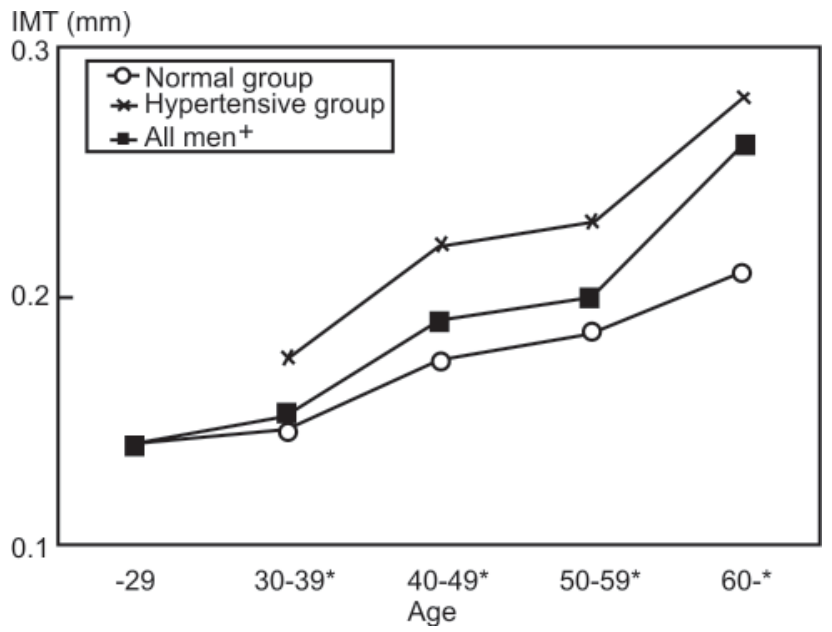

Fig. 3: The IMT of radial artery in 475 men

*Significant differences between normal and hypertensive groups $(p<0.01)$

+ In all men, significant differences between 30-39 and 40-49, 50-59 and over $60(p<0.01)$ 
Atsushi Yoshida et al

Table 1: Maximum and mean IMT in each pregnant groups

\begin{tabular}{|c|c|c|c|c|c|}
\hline & $n$ & Age $(y / o)$ & Gestational age (w) & Maximum IMT (mm) & Mean IMT (mm) \\
\hline Normal pregnancy & 35 & $30.5 \pm 5.6$ & $33.2 \pm 2.3$ & $0.54+0.10$ & $0.50 \pm 0.10$ \\
\hline Chronic hypertension & 22 & $32.3 \pm 6.9$ & $34.8 \pm 3.5$ & $0.74+0.18$ & $0.68 \pm 0.14$ \\
\hline Pre-eclampsia & 16 & $33.8 \pm 8.5$ & $33.0 \pm 2.6$ & $0.55+0.09$ & $0.50 \pm 0.09$ \\
\hline Pregestational diabetes & 22 & $31.5 \pm 3.7$ & $29.7 \pm 5.3$ & $0.86+0.36$ & $0.81 \pm 0.32$ \\
\hline Gestational diabetes & 18 & $30.8 \pm 2.9$ & $26.3 \pm 12.1$ & $0.67+0.31$ & $0.60 \pm 0.28$ \\
\hline
\end{tabular}

Data are expressed as mean $\pm \mathrm{SD}$

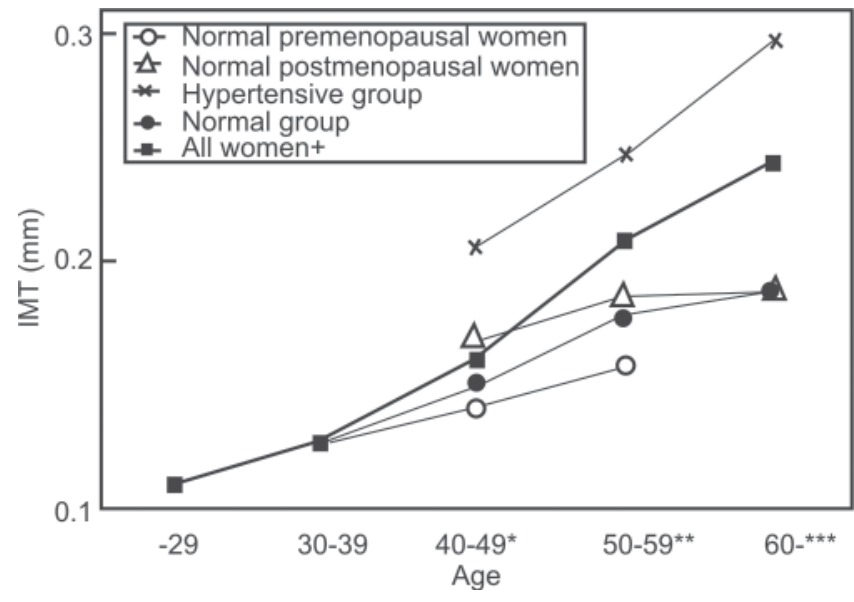

Fig. 4: The IMT of radial artery in 174 women.

All patients with hypertensive disorders was postmenopausal.

*Significant differences between normal premenopausal and hypertensive groups $(p<0.01)$ and between normal premenopausal and postmenopausal groups $(p<0.01)$.

${ }^{*}$ Significant differences between normal premenopausal and hypertensive groups $(p<0.01)$ and between normal postmenopausal and hypertensive groups $(p<0.01)$.

***Significant difference between normal and hypertensive groups $(p$ $<0.01$ ).

+ In all women, significant differences between 30-39 and 40-49, 4049 and $50-59(p<0.01)$

\section{Menopause and Vascular Endothelial Function}

Increased blood flow exerts the shear-stress on the endothelium and causes the release of endothelium-derived relaxing factor (EDRF) which is mainly nitric oxide. The EDRF acts on the vascular smooth muscle, increasing the vascular diameter, and decreased response to increased flow may reflect the impaired vascular endothelial function. Thus, we are able to assess the endothelial function noninvasively by measuring the vascular diameter change as a response to increased flow using highresolution ultrasound. The vascular response was called the flow-mediated vasodilation (FMD) and this method was introduced by Celermajer and colleagues, ${ }^{16}$ and a number of reports were published on the usefulness of this method in the assessment of endothelial function. Decreased FMD was reported to be associated with various diseases or situations

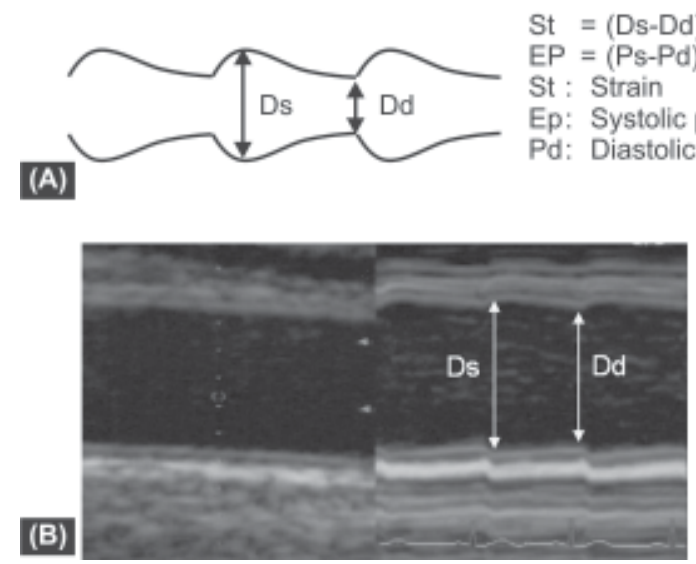

Fig. 5: Measuring methods of the elastic property in the common carotid artery.

$\mathrm{M}$-mode image was recorded from the longitudinal section of common carotid artery. Systolic and diastolic internal diameters of the common carotid artery (Ds, Dd) were measured. The strain and the elastic property of the common carotid artery were calculated from Ds, Dd, systolic pressure $(\mathrm{Ps})$ and diastolic pressure $(\mathrm{Pd})$. An example of $\mathrm{M}$ mode recording in common carotid artery is demonstrated (B)

complicated by such endothelial dysfunction as CAD, hypertension or diabetes mellitus.

The relationship between menopause and FMD was first reported by Celermajer and colleagues. ${ }^{17}$ In their report, FMD in women was stable until the early 50s, after which it gradually declined, and this decline was considered to be the effect of menopause. Subsequently many reports were published on the association between menopause and the decreased FMD. ${ }^{18,19}$

A number of reports have been published on the relationship between HRT and FMD. McCrohon and colleagues ${ }^{20}$ reported that long-term HRT is associated with improved arterial endothelial function in healthy postmenopausal women. Lieberman and colleagues ${ }^{21}$ reported that even short-term estrogen replacement therapy improves FMD in postmenopausal women. Significant relationship between estrogen replacement therapy and FMD was reported by many researchers, but progesterone was reported to exert no effects on FMD. ${ }^{22}$ Manolio and colleagues ${ }^{23}$ reported that HRT actually reduces CAD, but most of recent reports have shown that HRT did not reduce the incidence of CAD. ${ }^{24-26}$ 
The FMD was also reported to be influenced by certain gynecological diseases. Hashimoto and colleagues ${ }^{27}$ reported that FMD varied with the menstrual phase in premenopausal women. Kravariti and colleagues ${ }^{28}$ reported that FMD was decreased in women with polycystic ovary syndrome.

\section{Deep Vein Thrombosis in Gynecological Diseases and Surgeries}

Table 2 outlines clinical risk factors which are associated with the increased risk for deep vein thrombosis. ${ }^{29}$ Some gynecological situations as well as these factors are reported to increase the risk of thrombosis. These situations include prolonged surgery in the lithotomy position, large myoma or ovarian tumor, oral contraceptive, HRT and chemotherapy. At present, compression ultrasonography (CUS) is considered to be the most useful initial imaging test for the screening of venous thrombosis. Some of these gynecological factors are discussed below.

\section{Oral Contraceptive, HRT and Thrombosis}

The association between the oral contraceptive and venous thrombosis was first reported by Jordan in $1961^{30}$ and later epidemiological surveys supported the association. The overall risk for thrombosis in oral contraceptive users is reported to be increased threefold over that for nonusers and the risk is higher during early use. ${ }^{31}$ The risk is reported to be related to the dose of estrogen ${ }^{32}$ and the effort to reduce the estrogen dose had been made in order to minimize the risk for thrombosis. However, oral contraceptives of the latest generation (third generation) are reported to have a higher risk of thrombosis than those of second generation, despite their lowered androgenic effects. ${ }^{33}$

The HRT is also thought to increase the risk for venous thrombosis. Recent studies reported that HRT is associated with about twofold to fourfold higher risk for venous thrombosis. $^{34,35}$ The epidemiological trial by the Women's
Health Initiative (WHI) in the United States was initially planned to make a double-blind randomized study between the combined estrogen and progestin group and the placebo group for 8.5 years. However, the trial was discontinued earlier at the point of 5.2 years, as recommended by the data and safety monitoring board because of the health risks that exceeded health benefits. ${ }^{36}$ The WHI reported that the estimated hazard ratio of venous thromboembolic disease was 2.11.

It is not clearly shown that routine check-up for venous thrombosis by CUS is useful in oral contraceptive users or patients on HRT, but CUS may be useful for early detection of venous thrombosis in contraceptive users and HRT patients. We have recently started the routine check-up of CUS in the femoral and popliteal veins for outpatients on oral contraceptives or HRT in our Nishisaitama-Chuo National Hospital, where the number of subjects is small and we have had no case of thrombosis detected by CUS.

\section{Gynecological Cancer and Thrombosis}

The association between cancer and venous thrombosis was well known and the risk was said to be about two- to threefold. ${ }^{37,38}$ Ovarian cancer was reported to be one of the highest risks along with cancers of the liver, pancreas and brain. ${ }^{38,39}$ Recently, the association between ovarian cancer and thrombosis was reported in some publications. ${ }^{39,40}$ Gomes and colleagues ${ }^{41}$ reported that CUS was the best initial imaging test for suspected DVT in cancer patients. However, Bernstein and colleagues ${ }^{42}$ reported that CUS was not useful for the detection of DVT in asymptomatic cancer patients.

Gynecological surgery, especially surgery of malignant diseases is also one of risk factors of thrombosis. We are carrying out CUS of the femoral and popliteal veins for the screening of lower-extremity DVT in postoperative patients (Table 3). The incidence of DVT in our study is lower than that in previous reports, which may be the achievement of our prophylactic protocol (Fig. 6).

Table 2: Elastic property in each pregnant groups

\begin{tabular}{lllll}
\hline & $n$ & Age $(y / o)$ & Gestational age $(w)$ & Elastic property $(\mathrm{mmHg} / \mathrm{m})$ \\
\hline Normal pregnancy & 35 & $30.5 \pm 5.6$ & $33.2 \pm 2.3$ & $326 \pm 97$ \\
Chronic hypertension & 22 & $32.3 \pm 6.9$ & $34.8 \pm 3.5$ & $425 \pm 59$ \\
Pre-eclampsia & 16 & $33.8 \pm 8.5$ & $33.0 \pm 2.6$ & $366 \pm 112$ \\
\hline
\end{tabular}

Data are expressed as mean $\pm \mathrm{SD}$

Table 3: FMD in each pregnant groups

\begin{tabular}{|c|c|c|c|c|}
\hline & $n$ & Age (y/o) & Gestational age (w) & $F M D(\%)$ \\
\hline Normal pregnancy & 38 & $30.8 \pm 5.5$ & $33.7 \pm 2.3$ & $18.2 \pm 5.4$ \\
\hline Chronic hypertension & 16 & $32.3 \pm 6.9$ & $33.0 \pm 2.6$ & $7.8 \pm 8.0$ \\
\hline Pre-eclampsia & 22 & $33.8 \pm 8.5$ & $34.8 \pm 3.5$ & $3.8 \pm 1.4$ \\
\hline Pregestational diabetes & 25 & $31.5 \pm 3.7$ & $30.0 \pm 4.5$ & $5.8 \pm 2.2$ \\
\hline Gestational diabetes & 10 & $30.8 \pm 2.5$ & $28.5 \pm 7.0$ & $7.0 \pm 3.0$ \\
\hline
\end{tabular}

Data are expressed as mean $\pm \mathrm{SD}$ 


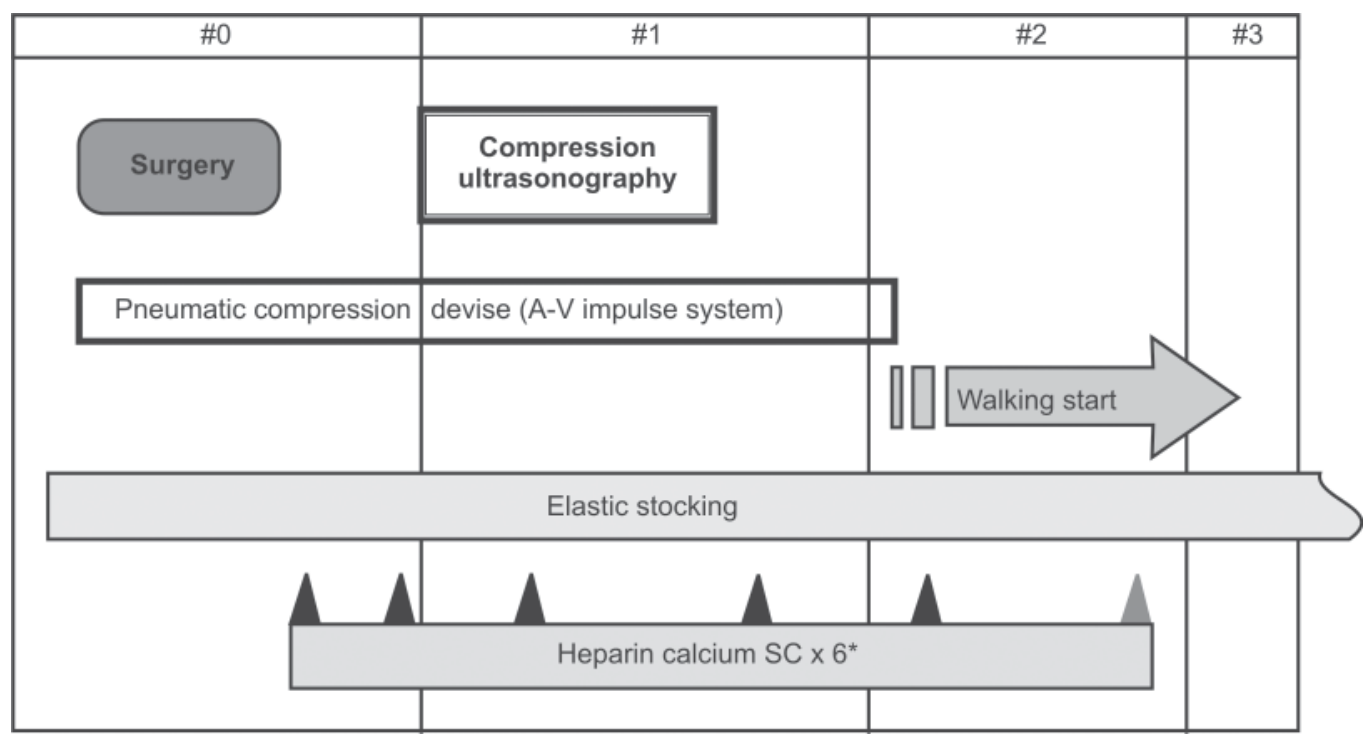

Fig. 6: Prevention protocol for deep vein thrombosis after gynecological surgery in Nishisaitama-Chuo National Hospital.

* The last heparin calcium administration is omitted in ambulatory patients

\section{REFERENCES}

1. Crouse JR, Harpold GH, Kahl FR, Toole JF, McKinney WM. Evaluation of a scoring system for extracranial carotid atherosclerosis. Stroke: 1986;17:270-5.

2. Pignoli P, Tremoli E, Poli A, Oreste P, Paoletti R. Intimal plus medial thickness of the arterial wall: a direct measurement with ultrasound imaging. Circulation 1986;74:1399-1406.

3. Salonen JT, Rauramaa R. Ultrasonographically assessed carotid morphology and the risk of coronary heart disease. Atheroscler Thromb 1991;11:1245-9.

4. Geroulakos G, O’Gorman DJ, Kalodiki E, Sheridan DJ, Kicolaides AN. The carotid intima-media thickness as a marker of the presence of severe symptomatic coronary artery heart disease. Eur Hear J 1994;15:781-5.

5. Joensuu T, Salonen R, Winblad I, Korlela H, Salonen JT. Determinants of femoral and carotid artery atherosclerosis. J Intern Med 1994;236;79-84.

6. MacKay AJ, Hamilton CA, McArthur K, Berg G, Tropeano AI, Boutouyrie P, Reid JL, Dominiczak AF. Radial artery hypertrophy occurs in coronary atherosclerosis and is independent of blood pressure. Clin Sci 2001;100:509-16.

7. Wildman RP, Schott LL, Brockwell S, Kuller LH, Sutton-Tyrrell K. A dietary and exercise intervention slows menopauseassociated progression of subclinical atherosclerosis as measured by intima-media thickness of the carotid arteries. J Am Coll Cardiol 2004;44:579-85.

8. Sator MO, Joura EA, Gruber DM, Wieser F, Jirecek S, Tschugguel W, Huber JC. The effect of hormone replacement therapy on carotid arteries: measurement with a high frequency ultrasound system. Maturitas 1998;30:63-8.

9. Le Gal G, Gourlet V, Hogrel P, Plu-Bureau G, Touboul PJ, Scarabin PY. Hormon replacement therapy use is associated with a lower occurrence of carotid atherosclerotic plaques but not with intima-media thickness progression among postmenopausal women. The vascular aging (EVA) study. Atherosclerosis 2003;166:163-70.

10. Nalulsi AA, Folsom AR, Szklo M, White A, Higgins M, Heiss G. No association of menopause and hormone replacement therapy with carotid artery intima-media thickness. Circulation. 1996;94:1857-63.

11. Dwyer KM, Nordstrom CK, Bairey Merz CN, Dwyer JH. Carotid wall thickness and years since bilateral oophorectomy: the Los Angeles Atherosiclerosis Study. Am J Epidemiol 2002;156:438-44.

12. Yoshida A, Kobayashi M, Kuroda K, Kobayashi H. Assessment of the intima-media thickness of radial artery using ultrasonography-Effects of aging and menopause. Jpn J Med Imaging, 2000;19,29-36.

13. Westendorp IC, Bots ML, Grobbee DE, Reneman RS, Hoeks AP, Van Popele NM, Hofman A, Witteman JC. Menopausal status and distensibility of the common carotid artery. Arterioscler Thromb Vasc Biol 1999;19:713-7.

14. Westendorp IC, de Kleijn MJ, Bots ML, Bak AA, Planellas J, Coelingh Bennink HJ, Hofman A, Grobbee DE, Witteman JC. The effect of hormone replacement therapy on arterial distensibility and compliance in perimenopausal women: a 2year randomised trial. Atherosclerosis 2000;152:149-57.

15. Angerer P, Kothny W, Stork S, von Schacky C. Hormon replacement therapy and distensibility of carotid arteries in postmenopausal women: a randomized, controlled trial. J Am Coll Cardiol 2000;36:1789-96.

16. Celermajer DS, Sorensen KE, Gooch VM, Spiegelhalter DJ, Miller OI, Sullivan ID, Llyod DJ, Deanfield JE. Noninvasive detection of endothelial dysfunction in children and adults at risk of atherosclerosis. Lancet 1992;340:1111-5.

17. Celermajer DS, Sorensen KE, Spiegelhalter DJ, Georgakopoulos D, Robinson J, Deanfield JE. Aging is associated with endothelial 
dysfunction in healthy men years before the age-related decline in women. J Am Coll Cardiol. 1994;24:471-6.

18. Al-Khalili F, Eriksson M, Landgren BM, Schenck-Gustafsson K. Effect of conjugated estrogen on peripheral flow-mediated vasodilation in postmenopausal women. Am J Cardiol 1998;15:215-8.

19. Blum A, Hathaway L, Mincemoyer R, Schenke WH, Kirby M, Csako G, Waclawiw MA, Panza JA, Cannon RO 3rd. Effects of oral L-arginine on endothelium- dependent vasodilation and markers of inflammation in healthy postmenopausal women. $\mathrm{J}$ Am Coll Cardiol 2000;35:271-6.

20. McCrohon JA, Adams MR, McCredie RJ, Robinson J, Pike A, Abbey M, Keech AC, Celermajer DS. Hormone replacement therapy is associated with improved arterial physiology in healthy post-menopausal women. Clin Endocrinol (Oxf) 1996;45:43541.

21. Lieberman EH, Gerhard MD, Uehata A, Walsh BW, Selwyn AP, Ganz P, Yeung AC, Creager MA. Estrogen improves endothelium-dependent, flow-mediated vasodilation in postmenopausal women. Ann Intern Med 1994;121:936-41.

22. Honisett SY, Pang B, Stojanovska L, Sudhir K, Komesaroff PA. Progesterone does not influence vascular function in postmenopausal women. J Hypertens 2003;21:1145-9.

23. Manolio TA, Furberg CD, Shemanski L, Psaty BM, O’Leary DH, Tracy RP, Bush TL. Associations of postmenopausal estrogen use with cardiovascular disease and its risk factors in older women. The CHS Collaborative Research Group. Circulation 1993;88:2163-71.

24. McPherson R. Is hormone replacement therapy cardioprotective? Decision-making after the heart and estrogen/ progestin replacement study. Can J Cardiol 2000;16 Suppl A:14A-19A.

25. Cho L, Mukherjee D. Hormone replacement therapy and secondary cardiovascular prevention: a meta-analysis of randomized trials. Cardiology 2005;104:143-47.

26. Ylikorkala O. HRT as secondary prevention of cardiovascular disease. Maturitas 2004;47:315-8.

27. Hashimoto M, Akishita M, Eto M, Ishikawa M, Kozaki K, Toba K, Sagara Y, Taketani Y, Orimo H, Ouchi Y. Modulation of endothelium-dependent flow-mediated vasodilation of the brachial artery by sex and menstrual cycle. Circulation 1995;92;3431-5.

28. Kravariti M, Naka KK, Kalantaridou SN, Kazakos N, Katsouras CS, Makrigiannakis A, Paraskevaidis EA, Chrousos GP, Tsatsoulis A, Michalis LK. Predictors of endothelial dysfunction in young women with polycystic ovary syndrome. J Clin Endocrinol Metab 2005;90:5088-95.

29. Jordan WH. Pulmonary Embolism. Lancet 1961;2:1146-7.

30. Kryle PA. Deep vein thrombosis. Lancet 2005;65:1163-74.

31. Bloemenkamp KW, Rosendaal FR, Helmerhorst FM, Vandenbroucke JP. Higher risk of venous thrombosis during early use of oral contraceptives in women with inherited clotting defects. Arch Intern Med 2000;160:49-52.

32. Thorogood M, Mann J, Murphy M, Vessey M. Risk factors for fatal venous thromboembolism in young women: a casecontrol study. Int J Epidemiol 1992;21:48-52.

33. Kemmeren JM, Algra A, Grobbee DE. Third generation oral contraceptives and risk of venous thrombosis: meta-analysis. BMJ 2001;21:131-4.

34. Hoibraaten E, Qvigstad E, Arnesen H, Larsen S, Wickstrom E, Sandset PM. Increased risk of recurrent venous thromboembolism during hormone replacement therapy-results of the randomized, double-blind, placebo-controlled estrogen in venous thromboembolism trial (EVTET). Thromb Haemost 2000;84:961-7.

35. Rosendaal FR, Van Hylckama Vieg A, Tanis BC, Helmehorst FM. Estrogen, progestogens and thrombosis. J Thromb Haemost 2003;1;1371-80.

36. Rossouw JE, Anderson GL, Prentice RL, LaCroix AZ, Kooperberg C, Stefanick ML, Jackson RD, Beresford SA, Howard BV, Johnson KC, Kotchen JM, Ockene J; Writing Group for the Women's Health Initiative Investigators. Risks and benefits of estrogen plus progestin in healthy postmenopausal women: principal results from the Women's Health Initiative randomized controlled trial. JAMA 2002;288:321-33.

37. Pruemer J. Prevalence, causes, and impact of cancer-associated thrombosis. Am J Health Syst Pharm 2005;62:S4-6.

38. Baron JA, Gridley G, Weiderpass E, Nyren O, Linet M. Venous thromboembolism and cancer. Lancet 1998;351:1077-80.

39. White RH, Chew HK, Zhou H, Parikh-Patel A, Harris D, Harvey $\mathrm{D}$, Wun T. Incidence of venous thromboembolism in the year before the diagnosis of cancer in 528,693 adults. Arch Intern Med 2005;165:1782-7.

40. Tateo S, Mereu L, Salamano S, Klersy C, Marone M, Spyropoulos AC, Piovella F. Ovarian cancer and venous thromboembolic risk. Gynecol Oncol 2005;99:119-25.

41. Gomes MP, Deitcher SR. Diagnosis of venous thromboembolic disease in cancer patients. Oncology 2003;17:126-35.

42. Bernstein R, Haim N, Brenner B, Sarig G, Bar-Sela G, Gaitini D. Venous sonography for the diagnosis of asymptomatic deep vein thrombosis in patients with cancer undergoing chemotherapy. J Ultrasound Med 2004;23:655-8. 